DOI: 10.1038/s41467-018-03030-4 OPEN

\title{
Publisher Correction: Role of outer surface probes for regulating ion gating of nanochannels
}

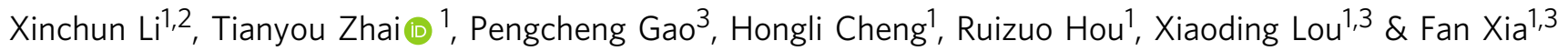

Correction to: Nature Communications https://doi.org/10.1038/s41467-017-02447-7, published online 03 January 2018

The original version of this Article contained an error in Fig. 3. The scale bars in Figs $3 \mathrm{c}$ and $\mathrm{d}$ were incorrectly labelled as $50 \mu \mathrm{A}$. In the correct version, the scale bars are labelled as $0.5 \mu \mathrm{A}$. This has now been corrected in both the PDF and HTML versions of the Article.

Published online: 08 February 2018

\begin{abstract}
(c) (i) Open Access This article is licensed under a Creative Commons Attribution 4.0 International License, which permits use, sharing, adaptation, distribution and reproduction in any medium or format, as long as you give appropriate credit to the original author(s) and the source, provide a link to the Creative Commons license, and indicate if changes were made. The images or other third party material in this article are included in the article's Creative Commons license, unless indicated otherwise in a credit line to the material. If material is not included in the article's Creative Commons license and your intended use is not permitted by statutory regulation or exceeds the permitted use, you will need to obtain permission directly from the copyright holder. To view a copy of this license, visit http://creativecommons.org/licenses/by/4.0/.
\end{abstract}

(c) The Author(s) 2018

\footnotetext{
${ }^{1}$ State Key Laboratory of Material Processing and Die \& Mould Technology, School of Material Sciences and Engineering, Hubei Key Laboratory of Bioinorganic Chemistry \& Materia Medica, School of Chemistry and Chemical Engineering, Huazhong University of Science and Technology (HUST), 430074 Wuhan, China. ${ }^{2}$ Pharmaceutical Analysis Division, School of Pharmacy, Guangxi Medical University, 530021 Nanning, China. ${ }^{3}$ Faculty of Materials Science and Chemistry, China University of Geosciences, 430074 Wuhan, China. Xinchun Li and Tianyou Zhai contributed equally to this work. Correspondence and requests for materials should be addressed to F.X. (email: xiafan@hust.edu.cn)
} 